Clinical Image

Oopen Access

A) CrossMark

\title{
Pasini-Pierini's atrophoderma and frontal fibrosing alopecia: an unusual association in a young patient
}

\begin{abstract}
A young woman of 38 years old, followed for fibrosing frontal alopecia under topical coricide, she had presented hypo pigmented macules at the abdominal level, back and thigh, whose histology had concluded a Pasini-Pierini atrophodermia. The association between fibrosing frontal alopecia and Pasinipierini atrophodermia is to our knowledge never described, whose physiopathology is unknown need more studies to explain this association.
\end{abstract}

Keywords: atrophoderma of Pasini-Pierini, frontal fibrosing alopecia, histology

\author{
Volume 4 Issue I - 2020
}

\section{A Rasso, Z Douhi, M Bennani, S Elloudi, H Baybay, Fz Mernissi}

Department of dermatology, University Hospital Hassan II Fez, Morocco Correspondence: Asmae Rasso, Department of Dermatology,
CHU Hassan II Fez, Morocco, Tel 00212 672314910,

Email rassoasma@gmail.com

Received: December 30, 2019 | Published: February 10, 2020

\section{Clinical image}

A 38-year-old woman, followed in our department for frontal Fibrosing alopecia confirmed by the clinic where she had front temporal scarring alopecia, with solitary hairs and follicular squamuson dermoscopy, put under topical corticosteroid with stabilization of the disease (Figure 1). She had consulted in her control examination after the appearance of asymptomatic whitish lesions. There was no history of trauma, infection or ulceration at the sites. Skin examination revealed multiples hypo pigmented plaques of varying sizes (2$6 \mathrm{~cm})$ on the back and thighs. These patches were well defined. There was no induration, no tenderness, but slight atrophy was seen. The lesions were not progressive (Figure 2). Laboratory examination, including a total and differential lymphocyte count and an erythrocyte sedimentation rate test, was within normal limits. Histopathological examination revealed epidermal atrophy, hyalinization of collagen in the dermis with minimal scattered inflammatory infiltrate. The thickness of the dermis was slightly reduced compared to that of normal adjacent skin. A diagnosis of Pasini and Pierini's atrophoderma associated with fibrotic frontal alopecia was made on the basis of clinical, dermoscopie and histopathological examination.

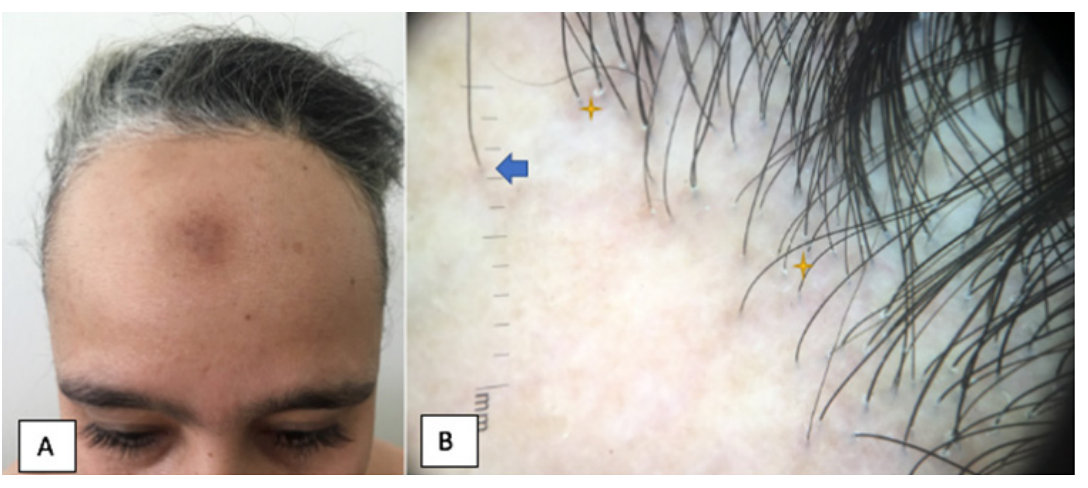

Figure I (A) frontal fibrosing alopecia. (B) the blue arrow showed a solitary hairs, and yellow star showed a follicular squamous.

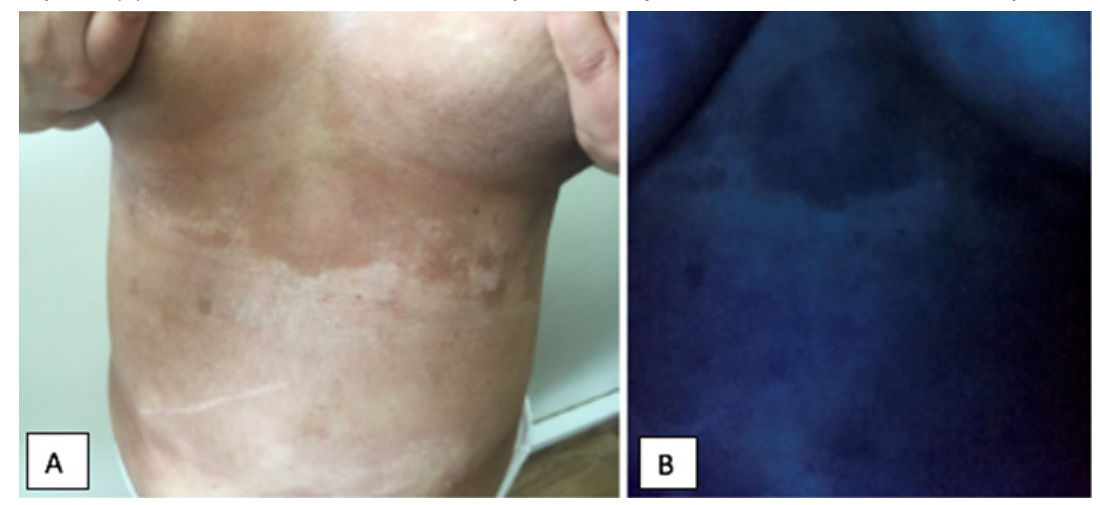

Figure 2 Pasini and Pierini's atrophoderma with multiples hypo pigmented plaques. 
Frontal Fibrosing alopecia is a scarring lymphocytic alopecia, considered a type of lichen pilaris, the etiology is unknown, it affects pre- or post-menopausal women with a suggested hormonal cause. Clinically, it is a linear frontal-temporal scarring alopecia, with some solitary hairs, sometimes there is an extension of the eyebrows and eyelashes. Dermoscopy shows the presence of perifollicular erythema, or at a late stage perifollicular hyper-pigmentation, perifollicular flakes..$^{2-3}$ However, Pasini and Pierini's atrophoderma is a rare skin condition that causes dermal atrophy. Pasini described it in 1923 as "progressive idiopathic atrophoderma". ${ }^{4}$ Pierini and Vivoli later described it in 1936, suggesting its possible link to morphea. It presents as single or multiple, clearly defined, hyperpigmented, non-indurated, non-indurated plaques with no obvious inflammatory signs. The association of these two diseases has never been described to our knowledge, suggests a pathophysiology that may be common and further studies and case reports are needed to explain the cause of this association.

\section{Conflicts of interest}

The authors report no conflicts of interest.

\section{Acknowledgments}

None.

\section{Funding}

None.

\section{References}

1. Vano-Galvan S, Molina-Ruiz AM, Serrano-Falcon C, et al. Frontal fibrosing alopecia: a multicenter review of 355 patients. $J$ Am Acad Dermatol. 2014;70(4):670-678.

2. Fernandez-Crehuet P, Rodrigues-Barata AR, Vano-Galvan S, et al. Trichoscopic features of frontal fibrosing alopecia: results in 249 patients. J Am Acad Dermatol. 2015;72(2):357-359.

3. Sonthalia S, Jha AK, Tiwary PK. A Dermoscopic Diagnosis and Activity Evaluation of Frontal Fibrosing Alopecia in an Indian Lady. Indian Dermatol Online J. 2017;8(2):162-163.

4. Pasini A. Atrophoderma idiopathica progressive. G Ital Dermatol. 1923;58:785-809.

5. Saleh Z, Abbas O, Dahdah MJ, et al. Atrophoderma of Pasini and Pierini: a clinical and histopathological study. J CutanPathol. 2008; 35(12):1108-1114 